\title{
Integrated Resource Planning for a Chinese Urban Development
}

\author{
Thomas Ravalde and Dr James Keirstead \\ Department of Civil and Environmental Engineering, Imperial College London, UK \\ http://discovery.ucl.ac.uk/1469209/
}

\begin{abstract}
Urban areas manage vast quantities of energy, water and waste resources. In order to minimise the cost and environmental impact, optimisation modelling is often used in the design and operation of these systems. However, traditional modelling approaches only consider the energy, water and waste sectors in isolation. This approach neglects the synergies possible between these systems whereby outputs from one system form an input to another, and hence sets an upper bound on economic and environmental impact minimisation. We formulate a mixed integer linear programming (MILP) model which takes a 'systems-of-infrastructure systems' approach to show how resource consumption can be reduced. The model takes as inputs possible resource conversion and transportation infrastructure and resources, and resource demands, and returns the optimal infrastructure choice and layout. The model is called PRaQ because it models 'processes, resources and qualities.' We apply the model to the design of a new urban development in China for three scenarios of various levels of resource integration. Results are still to be obtained.
\end{abstract}

Keywords: Infrastructure, Optimization, Modelling, Urban Resource Management, Industrial Symbiosis

\section{INTRODUCTION}

Cities perform a vital socioeconomic role in human civilisation. Currently home to about half of the world's population, they generate around $80 \%$ of global GDP ${ }^{1}$, and are a proven means for improving quality of life as people seek health, economic, educational and other benefits. Accordingly, the globe's urban population is forecasted to rise to around $70 \%$ in 2050². To achieve this level of urban growth, vast quantities of energy, water and waste must be consumed to support basic services and economic activity. This poses significant environmental challenges, including resource scarcity, poor water quality, air pollution ${ }^{3}$, water stress ${ }^{4}$, decreasing waste management capacity, and greenhouse gas emissions. Additionally, high levels of resource consumption pose an economic risk to an area, as a population outgrows its resource supply, imposing a limit on growth ${ }^{5}$.

The management of these energy, water and waste flows requires conversion, transport and storage infrastructures, and as such, efforts to reduce resource consumption are (in part) focused on better design and management of these systems. Traditionally, work in this area has tended to be siloed within individual infrastructure systems. However, in urban areas,

\footnotetext{
1 United Nations. World urbanization prospects. (2011).

2 World Bank. World development reports. (2009).

3 Cao, S. \& Li, C. The exploration of concepts and methods for low-carbon eco-city planning. Procedia Environmental Sciences. 5, 199-207 (2011).

4 Kennedy, C. The changing metabolism of cities. J Ind Ecol. 11(2), 43-59 (2007).

5 Bettencourt, L. M., Lobo, J., Helbing, D., Kühnert, C., \& West, G. B. Growth, innovation, scaling, and the pace of life in cities. Proc Nat/ Acad Sci U.S.A.. 104(17), 7301-7306 (2007).
} 
the co-location of infrastructure enables synergies between networks, whereby the output from one sector becomes an input to another. (Examples include waste-to-energy, biogas from sewage sludge, hydroelectric power, wastewater reuse $^{6}$, and 'industrial symbiosis' ${ }^{7}$.) Therefore, current approaches to urban resource management impose an upperbound on the material and energy savings that are possible.

In this paper, we attempt to move beyond the traditional sector-specific focus on resource efficiency and examine integrated management of energy, water and waste infrastructures. Our objective is to develop an optimization model that can maximise opportunities for systems integration, and by applying it to a case study in urban China, to quantify the potential gains of such an approach under different development scenarios. We begin by discussing the current state of urban resource systems modelling and offer our proposed modelling framework. Next, we introduce a case study of a new urban development in China and describe how the model is applied. Finally, we present the results and summarise our conclusions.

\section{MODELLING URBAN RESOURCE SYSTEMS}

The literature contains a wide variety of energy, water and waste planning models but lacks tools which meet demand for all three resource types simultaneously. To deal with multiple resource types in this manner, we require the model to have a very generic formulation. For this reason, we base our work on that of Samsatli and Jennings (2013) (which is applied in Keirstead et al (2012) $)^{9}$. Thus it is based on a state-task network chemical engineering process model ${ }^{10}$, where 'states' represent any material with a given set of properties, and 'tasks' represent processes that convert a set of input states to a set of output states (Figure 1). Samsatli and Jennings apply this approach to urban energy systems, representing them as a network of resources (states) and technologies (tasks). A resource represents any material or energy streams involved in meeting energy demand.

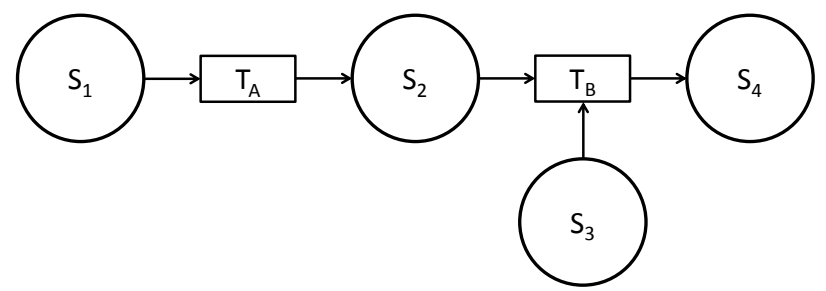

Figure 1. A state-task network. States denoted by 'S'; tasks denoted by 'T'.

Here, we extend this formulation beyond energy resources to include water and waste, with demand for each of energy, water and waste management being met. Thus, gas, electricity, heat, water, wastewater, municipal solid waste and $\mathrm{CO}_{2}$ can all be considered resources. Processes are used to represent any activity that can convert a set of input resources to a set of output resources. For example, Figure 1 could represent a power plant $\left(T_{A}\right)$, which takes coal $\left(S_{1}\right)$ as input, and produces electricity $\left(\mathrm{S}_{2}\right)$; the electricity is fed into a wastewater-source heat pump $\left(\mathrm{T}_{\mathrm{B}}\right)$ along with wastewater $\left(\mathrm{S}_{3}\right)$, from which heat $\left(\mathrm{S}_{4}\right)$ is extracted. Processes also model the transport of resources using similar methods to evaluate the resource requirements and losses involved in transport networks (such as pipes and cables).

In addition to a broader range of resources, a further development to Samsatli and Jennings' model is the incorporation of resource quality modelling. For example, when pumping water, pipe-wall friction will reduce the water's energy head. In an integrated model, where the pumping energy will be a decision variable (together with the mass of water pumped), it is important to consider these energy losses, as this will impact the primary resources used in energy generating processes. Thus each resource must have at least one quality attribute corresponding to the resource properties we are concerned with. The model's inclusion of processes, resources and qualities gives rise to its name 'PRaQ' ('processes, resources and qualities'). To use the model, we must specify:

6 Kharrzi, A. \& Masaru. Y. Quantifying the sustainability of integrated urban waste and energy networks: seeking an optimal balance between network efficiency and reslience. Procedia Environmental Sciences. 13, 1663-1667 (2012).

7 Eckelman, M. J. \& Chertow, M. R. Life cycle energy and environmental benefits of a US industrial symbiosis. Int J Life Cycle Assess. 18(8), 1524-1532 (2013).

8 Samsatli, N. \& Jennings, M.G. 'Optimization and systems integration' in Keirstead and Shah (eds) Urban Energy Systems: An Integrated Approach. Routledge (2013).

9 eirstead, J., Samsatli, N., Pantaleo, A. M. \& Shah, N. Evaluating biomass energy strategies for a UK eco-town with an MILP optimization model. Biomass Bioenerg. 39, 306-316 (2012).

10 Kondili, E., Pantelid, C. \& Sargent, R. A general algorithm for short-term scheduling of batch operations I. MILP Formulation. Comput Chem Eng. 17(2), 211-227 (1993). 
- resource demands for each zone of the study area, and time period;

- a set of allowable conversion and transport processes and their associated resources;

- coefficients to relate the input and output resource quantities and qualities for each process;

- the costs and emissions of resource imports;

- the cost for process capital, operation and maintenance;

- constraints on the minimum and maximum rate of process operation, and the location of imports, exports and processes;

- an objective function that minimises cost, emissions or some other indicator.

Given these inputs, the model will return an optimal resource-process network configuration, process operating rates, resource import/export schedules, and a summary of system performance metrics.

\section{A CASE STUDY: THE SHANNGU URBAN DEVELOPMENT}

The intention of $\mathrm{PRaQ}$ is that it can be used as a strategic planning tool, to support engineers and architects at the early stages of urban planning, most ideally for the case where one decision maker is responsible for all the management of all resource types. This is the organisational structure for a new urban development managed by the ShaanGu Power Company $L_{t d}{ }^{11}$. Historically they manufacture machinery, but more recently they have expanded into utility service provision, managing the energy, water and waste for the redevelopment of an old industrial park in China.

\section{MODEL SCENARIOS}

Three scenarios will be studied in order to evaluate the potential savings of alternative technology configurations. Each scenario will specify the same demands for heating, cooling, electricity, water, waste management and wastewater treatment. However they will vary in terms of the allowable set of input technologies:

- Grid case. This will meet demand by using technologies that require directly imported resources (for example a gasfuelled domestic boiler). This represents a 'business-as-usual' scenario.

- Design case. This uses technologies which can reuse outputs from other processes. For example, a water-source heat pump (to provide heating) can be served by wastewater. This case is based on a design proposal by the ShaanGu Power Company.

- Wildcard case. This combines the above two technology sets.

For each scenario, the model is run to find the system that minimises the combined capital, operating and resource import costs.

\section{RESULTS, DISCUSSION AND CONCLUSIONS}

By comparing the results of each scenario, we show that for a given level of utility service demand, cost savings can be made through integrated resource planning (Figure 1). A closer examination of the resource imports (Figure 2) shows that this is because the grid case relies on large import quantities of electricity (for cooling) and gas (for heating). The other scenarios (design and wildcard) integrate together the water and energy systems through the use of a water-source heat pump, with the result that the area is less reliant on resource imports.

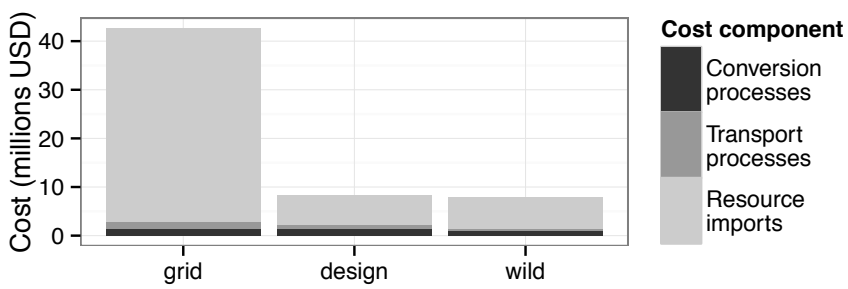

Figure 2. Annualised cost for each scenario.

11 http://www.shaangu.com 


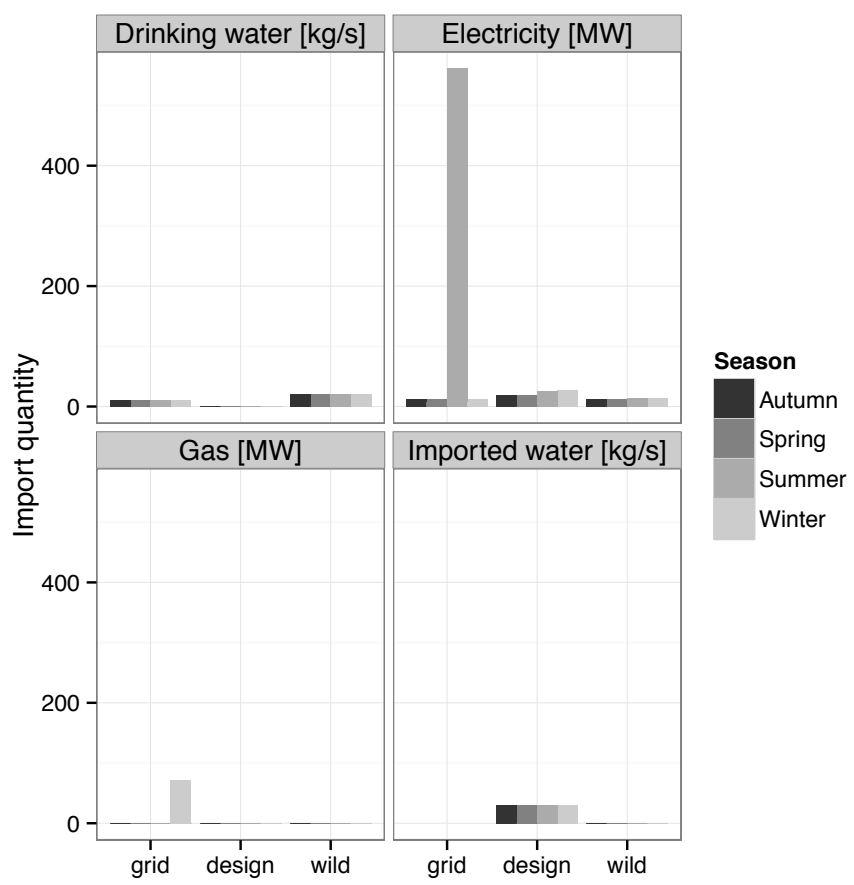

Figure 3. Resource imports for each scenario (by season).

In conclusion, there is a growing awareness that the key to more efficient urban resource is a 'system-of-systems' approach, integrating the operation of urban resource infrastructures, that convert, transport and store energy, water, and waste. However there are currently no well-established tools for analysing such infrastructure configurations. The work presented here therefore builds on optimisation techniques that have demonstrated significant savings in the energy sector, and extends them to consider the integrated planning of multiple resource infrastructures. Accordingly the benefits of a 'system-of-systems' approach can be quantified according to chosen metrics, allowing stakeholders to explore a range of alternatives. More generally, $\mathrm{PRaQ}$ can enable us to develop a better appreciation for the key technological interventions (such as the water-source heat pump in this case study) that unlock wider resource efficiency in the urban environment.

Turning to consider the future of infrastructure, $\mathrm{PRaQ}$ can contribute to meeting the 'Grand Challenge' set out by the International Symposium for Next Generation Infrastructure ${ }^{12}$. $\mathrm{PRaQ}$ is a tool which moves us towards realising 'infrastructure systems that can meet the needs of twice today's population with half today's resources'. Its offering is a modelling framework which considers the 'web of interdependencies and interconnections' between multiple types of physical infrastructure, thus adopting a 'genuine systems perspective' rather than 'traditional disciplinary and sectoral' approaches.

However, in order to be effective, this work must overcome the potentially conflicting interests of multiple decision makers. In the case study presented here, one firm manages all the resources for the urban development; but elsewhere in the world (for example, the United Kingdom) energy, water and waste infrastructures are operated by different companies, each with their own objectives. Thus, the physical 'system-of-systems' approach here should be incorporated into the broader economic and social 'system-of-systems' which dictate how infrastructure is organised. The ultimate aim being that through policy, planning, and institutional reform, we can move to a society that can fully embrace integrated resource planning, and realise the potential for mitigating against environmental problems and economic risk whilst retaining the socioeconomic benefits of urbanisation.

\section{ACKNOWLEDGEMENTS}

The data for the model has been provided by the ShaanGu Power Co., Ltd, in collaboration with Dr Yingru Zhao of The School of Energy Research, Xiamen University. The authors would like to acknowledge Dr Nouri Samsatli for developing the original TURN model formulation and thank him for providing the GAMS code, which we modified for this study.

12 http://www.ucl.ac.uk/steapp/isngi/grandchallenge 